\title{
FEATURE Adapting agriculture to drought and extreme events
}

\author{
Rattan Lal, Jorge A. Delgado, Jim Gulliford, David Nielsen, Charles W. Rice, and R. Scott Van Pelt
}

$\mathbf{T}$ he 2012 drought, one of the worst during the last 80 years or more, reminds us of the dust bowl of the 1930s (figure 1) and indicates that climate change is a reality rather than a distant threat. The drought has had a severe impact on yields, reducing the predicted grain production for corn per acre at a farm level to levels of production that have not been seen since 1995 and severely impacting other crops such as soybeans. Analysis has predicted that these lower yields will contribute to spikes in wholesale prices for consumers in the United States and internationally since the United States is the world's leading exporter of these grains. It is projected that prices for meat, eggs, and milk will also increase as a result of the drought impacts on grain yields, animals, and forages among other factors.

Many view the 2012 drought as an extension of the exceptional drought of 2011 in Texas and surrounding regions, during which 7.5 million ac $(3$ million ha) succumbed to wildfire in Texas, New Mexico, and Arizona. Additionally, many expect that these droughts will be the new norm during this century. These droughts are following recent droughts like the 2003 to 2004 drought that was the worst in more than 800 years (Schwalm et al. 2012). With business as usual, a drought of this duration, extent, and severity will be a common occurrence throughout the 21 st century and beyond. These droughts may be occasionally interrupted by seasons of excessive rains and widespread

Rattan Lal is a distinguished university professor in the School of Environment and Natural Resources, Ohio State University, Columbus, Ohio. Jorge A. Delgado is a soil scientist at the USDA Agricultural Research Service, Fort Collins, Colorado. Jim Gulliford is the executive director of the Soil and Water Conservation Society, Ankeny, lowa. David Nielsen is a research agronomist at the USDA Agricultural Research Service, Akron, Colorado. Charles W. Rice is a distinguished university professor and a professor of soil microbiology at Kansas State University, Manhattan, Kansas. R. Scott Van Pelt is a soil scientist at the USDA Agricultural Research Service, Big Spring, Texas.

\section{Figure 1}

Example of a catastrophic wind storm event during the 1930s Dust Bowl era. (Photo courtesy of USDA Natural Resources Conservation Service, http://photogallery.nrcs. usda.gov).

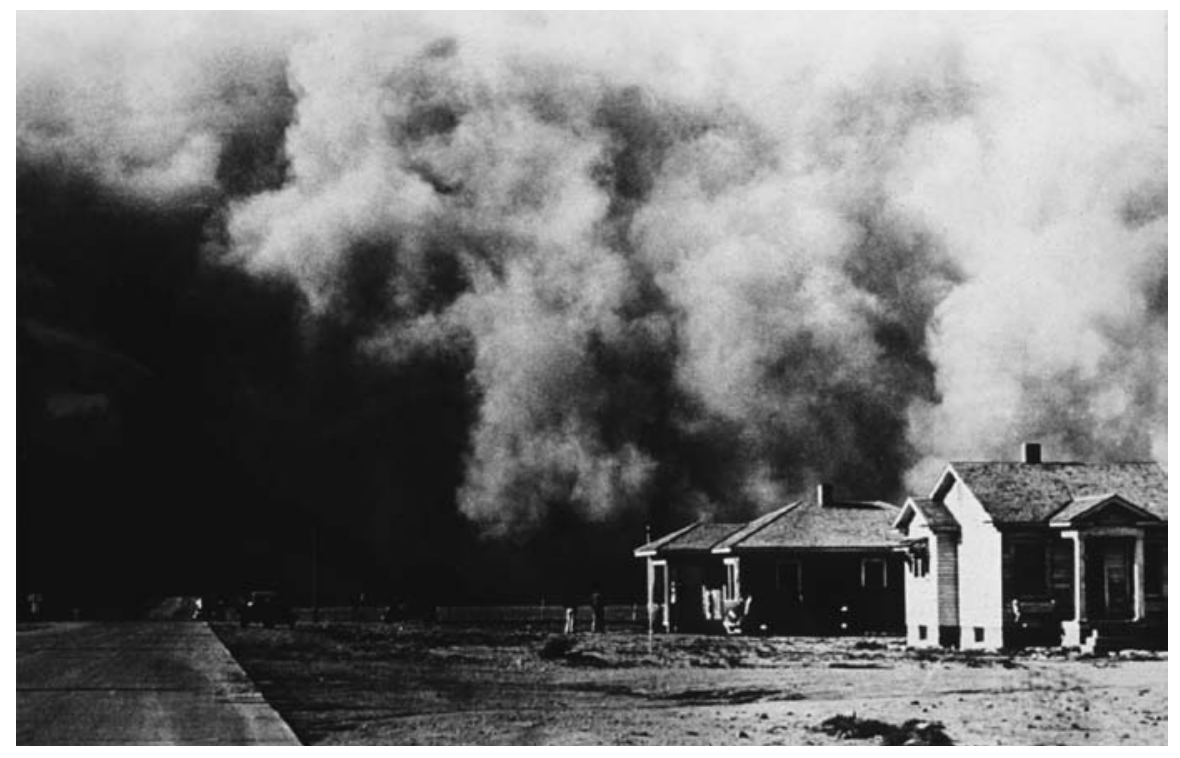

inundation, as has been the case in 2011 in the central United States and this summer in the United Kingdom. It is widely argued that the type of extreme events characterized by the 2012 drought in the United States and flooding in the United Kingdom could become the new normal because of the human-induced climate change. The drought, accompanied by the fourth warmest winter with record high temperatures in March 2012, has also caused widespread wildfires (figure 2) in Colorado and in the western United States. July 2012 was the hottest month in the lower 48 states since the record began in 1895. In addition to the duration and severity, it is its extent or the breadth that is alarming.

The area covered by one of the worst droughts on record stretched across $77.5 \%$ of the contiguous United States (as of September 9, 2012), with conditions ranging from abnormally dry (D0) to exceptional drought (D4) (figure 3). For most of the area covered by the Corn Belt, conditions started off with a warm spring season, which could potentially be beneficial for fast growth, but conditions then developed into a growing season of severe to exceptional drought (D2-D4; see figure 3). Forty-two percent of the contiguous Unites States is impacted with severe (D2) to exceptional (D4) drought conditions. This area of very intense drought extends from the Colorado Rockies through the Great Plains and reaches across the Mississippi and Ohio River valleys (D2-D4; see figure 3). Most of the extreme to exceptional drought conditions (about 80\%) are located across Colorado, Nebraska, Kansas, Oklahoma, Iowa, Missouri, Arkansas, Illinois, and Indiana.

\section{PREDICTED IMPACTS ON YIELDS}

Conditions have been so severe that as of September 5, 2012, there have been 1,820 counties in the United States designated by the Secretary of Agriculture as disasters areas due to drought (figure 4; USDA 2012a). The 2012 growing season, which began with the highest area planted in corn in the United States since 1937, is now projected to have $13 \%$ less corn production than the 2011 growing season (USDA $2012 \mathrm{~b})$. The USDA has projected that as of 


\section{Figure 2}

Remote sensing picture showing (a) extended areas covered by several wildfires during the 2012 drought season in western United States and (b) areas covered by smoke in Colorado (notice smoke traveling east toward Wyoming and Nebraska). (Photos courtesy of National Aeronautics and Space Administration)
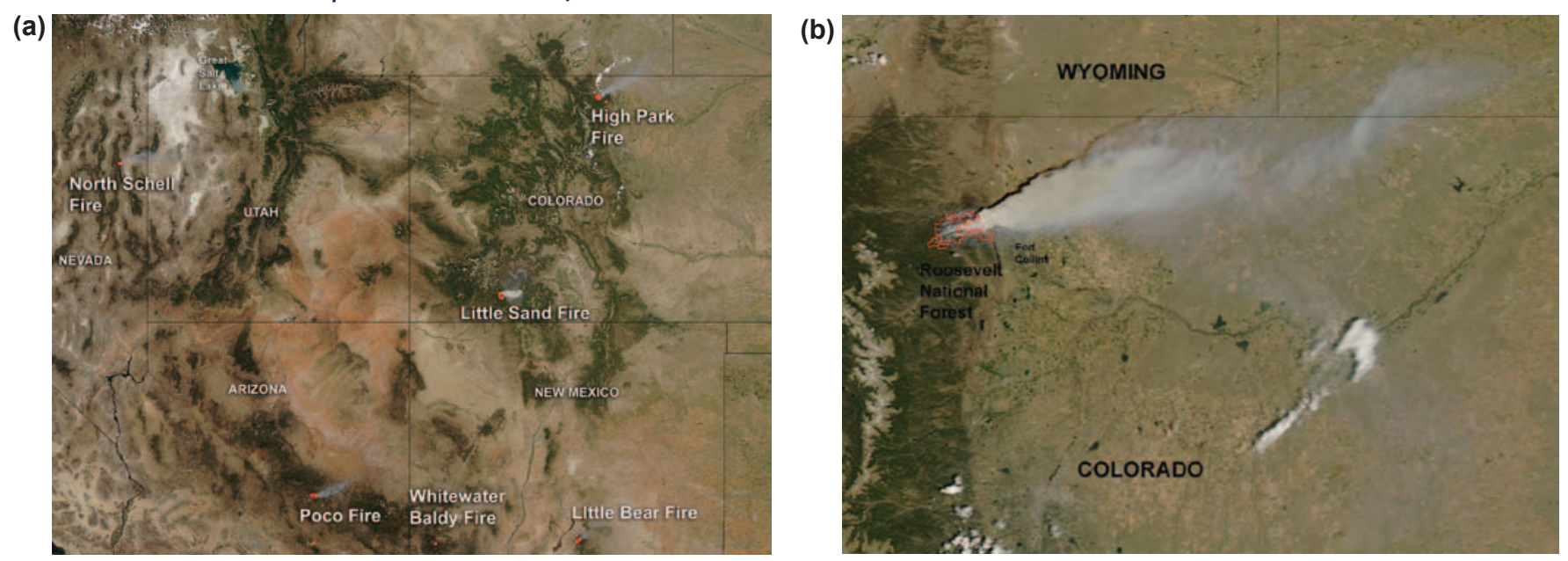

\section{Figure 3}

Drought severity levels across the United States. Notice the severity and extensiveness of drought across the middle region of the United States that extends from the Colorado Rockies, across the Great Plains, and to the Mississippi and Ohio River valleys (Simeral 2012).

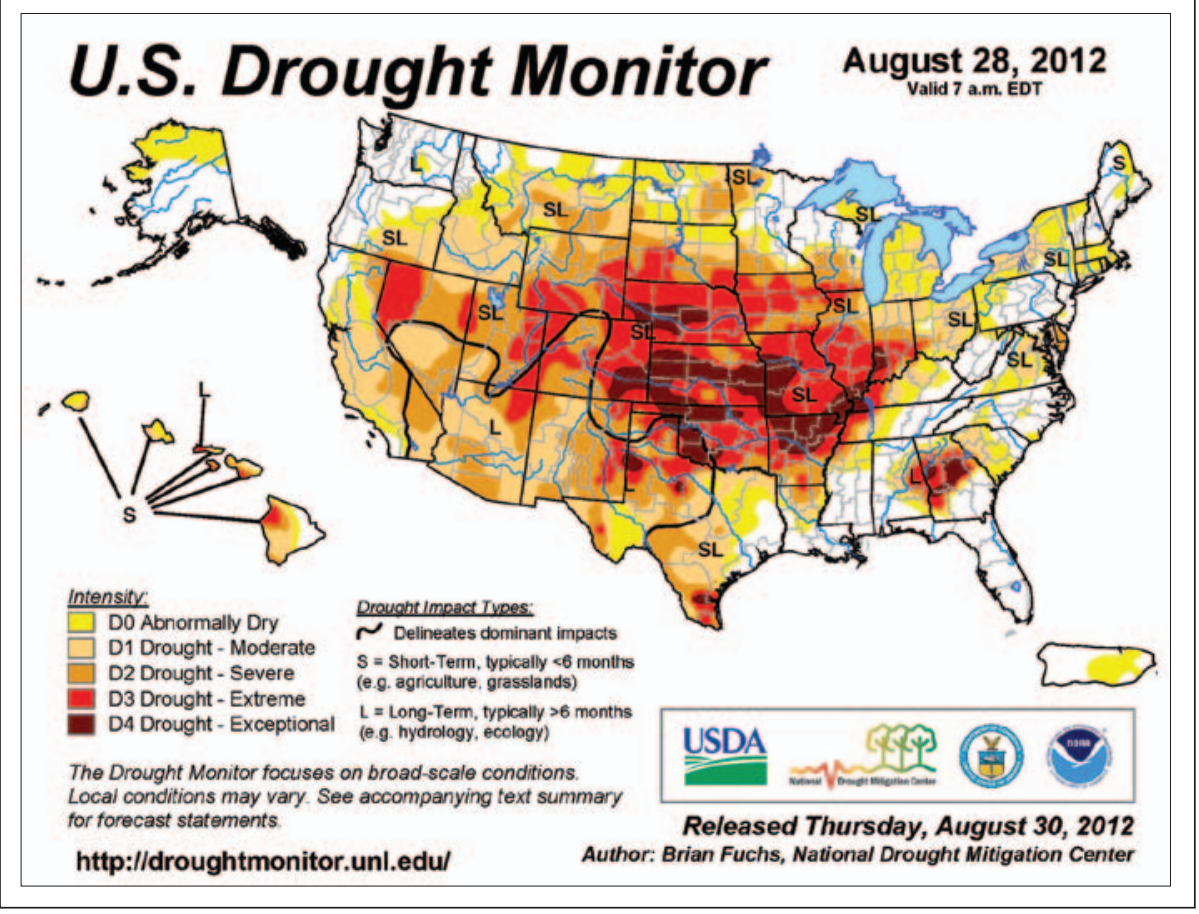

September 10, 2012, for the primary states producing corn, sorghum, cotton, and soybean, $52 \%, 51 \%, 30 \%$, and $36 \%$ of the crop will be in poor or very poor conditions, respectively (USDA 2012b).

Animal feed will be significantly impacted since across the contiguous
United States about $58 \%$ of the pasture and rangeland was in poor or very poor conditions, with ten states having over $75 \%$ of their pasture and rangeland in poor or very poor conditions.

In Texas alone, the 2011 drought resulted in over US $\$ 7.6$ billion of agri- cultural losses. The US Secretary of Agriculture listed 252 of the 254 total counties as primary disaster areas and the remaining 2 counties as contiguous on July 12, 2012. Most of Texas remains in drought, although not exceptional drought as in 2011. As of September 10, 2012, eighteen states are completely covered with counties designated as either primary disaster areas or contiguous. The 2012 drought has jeopardized $52 \%$ of the corn (figure 5), 36\% of soybean, 51\% of sorghum (figure 6), 30\% of cotton (figure 7 ), and $58 \%$ of the pasture and rangeland. Rangelands, especially in the Great Plains and the southwestern regions, have also been devastated (figure 8). As of September 12,2012 , projected crop yields in the 2012 growing season are expected to be severely reduced, with soybean yields of $2,214 \mathrm{~kg}$ $\mathrm{ha}^{-1}\left(35.3 \mathrm{bu} \mathrm{ac}^{-1}\right)$ being the lowest since 2003 and corn yields of 8,252 $\mathrm{kg} \mathrm{ha}^{-1}$ (122.8 bu ac${ }^{-1}$ ) being the lowest since 1995 (USDA 2012c).

\section{FOOD SECURITY}

Agriculture may be adversely affected also because of the residual effects of a severe drought and the multiyear trends in rainfall and other weather components (e.g., temperature, wind, solar radiation, evaporation). Low crop yields have raised fears whether the world is on the tipping point of another food crisis similar to the one experienced in 2007 and 2008. Agricultural 


\section{Figure 4}

The 2012 Secretarial Drought Designations across the United States as of September 5 , 2012. Notice that the majority of counties in the United States were impacted, and that many states had $100 \%$ of their counties impacted by drought. A narrow-banded region that was not impacted by drought extends from Louisiana to the northeastern United States. There is a second nonimpacted area along the American/Canadian border. The rest of the contiguous United States is impacted by drought. (USDA 2012a)

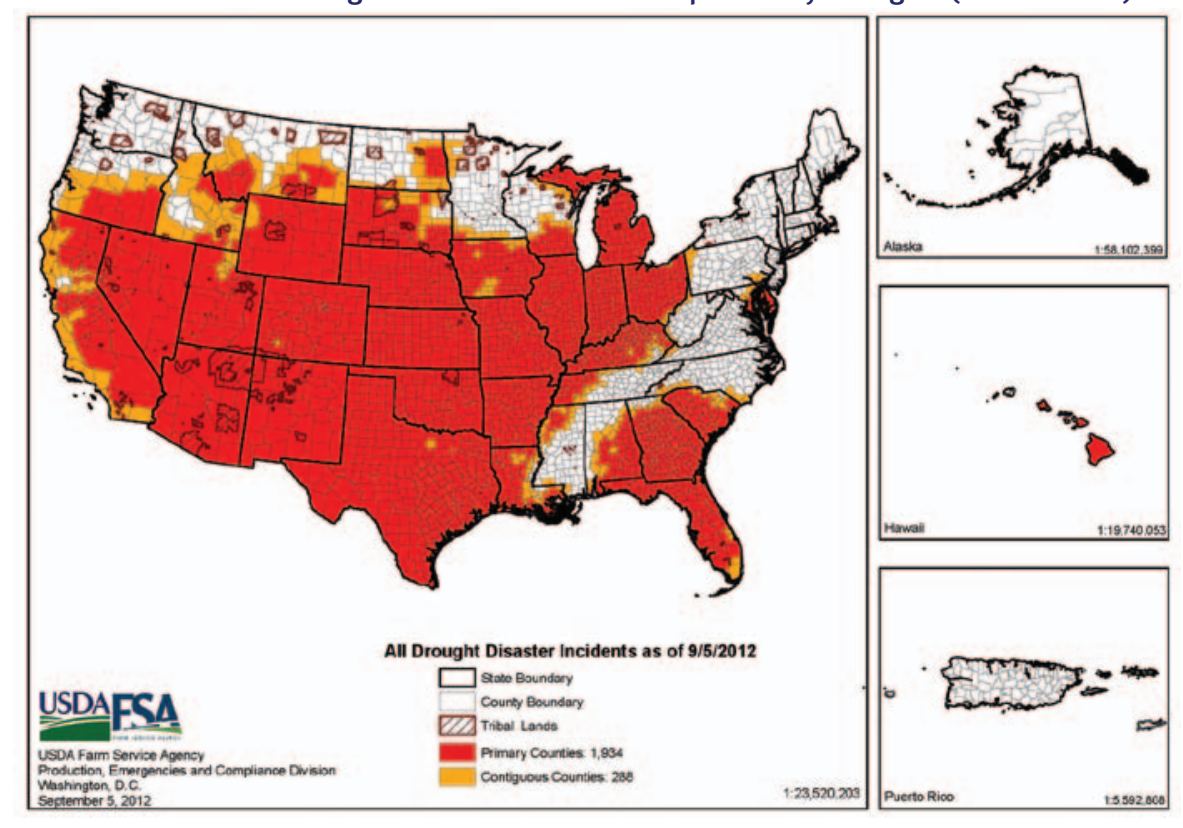

\section{Figure 5}

Example of a corn crop impacted by the catastrophic 2012 drought (Kansas).

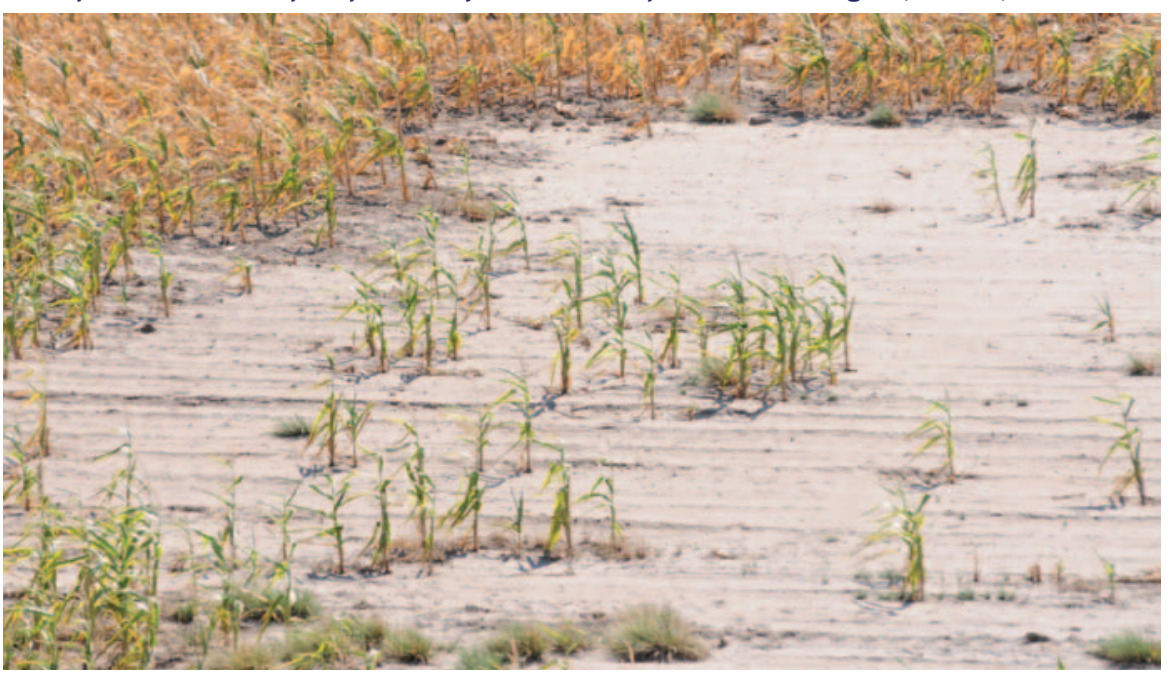

commodity prices may increase by $20 \%$ to $30 \%$, putting low-income communities under great financial stress. Increase in the price of feed may also increase the price of meat, poultry, and other animal-based food products. Meat prices are already increasing as herds sold and slaughtered to protect fragile and drought-affected rangeland two years ago have limited the

\section{Figure 6}

Example of a sorghum crop impacted by the catastrophic 2012 drought in (a) Kansas and (b) Texas.

(a)

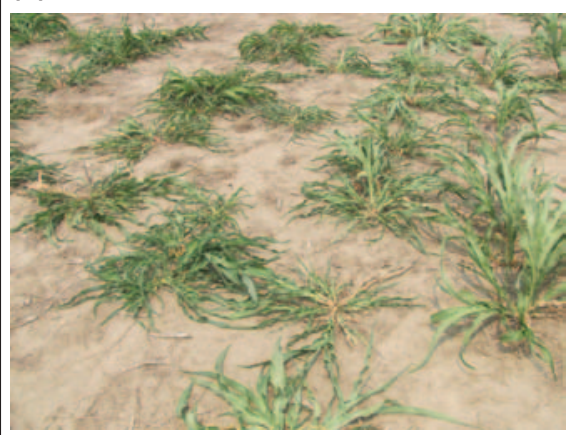

(b)

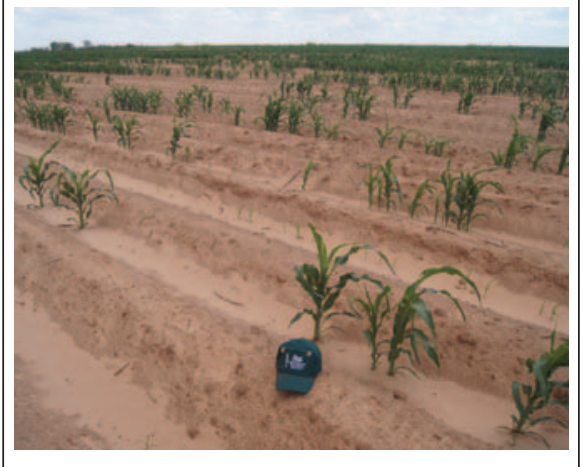

more than $3 \mathrm{~m}(10 \mathrm{ft})$ during the summer of 2012. Many reservoirs supplying municipal drinking water in West Texas are dry and others are below 10\% capacity, resulting in draconian water rationing measures. In addition to the restrictions on using water for lawns, golf courses, and car washes, there is a scarcity of water for irrigating grains and horticultural crops. In the United States, irrigated cropland produces approximately $53 \%$ of the market value of crops harvested on $17 \%$ of the cropland, and fully irrigated farms produce about $40 \%$ of the value on $9 \%$ of the land. Severe and multiyear droughts reduce the available water (both surface and ground) for irrigation and jeopardize the productivity of irrigated croplands. Further, the Mississippi River flow rate is shrinking under the worst drought in recent history, making it increasingly difficult to keep the traffic moving. This set of hydrologic consequences is particularly alarming since hydrologic drought recovery typically takes years longer than soil drought recovery and requires several sequential years of above-average rainfall. Thus, how can agri- 


\section{Figure 7}

Example of a dryland cotton crop impacted by the catastrophic 2012 drought in west Texas.

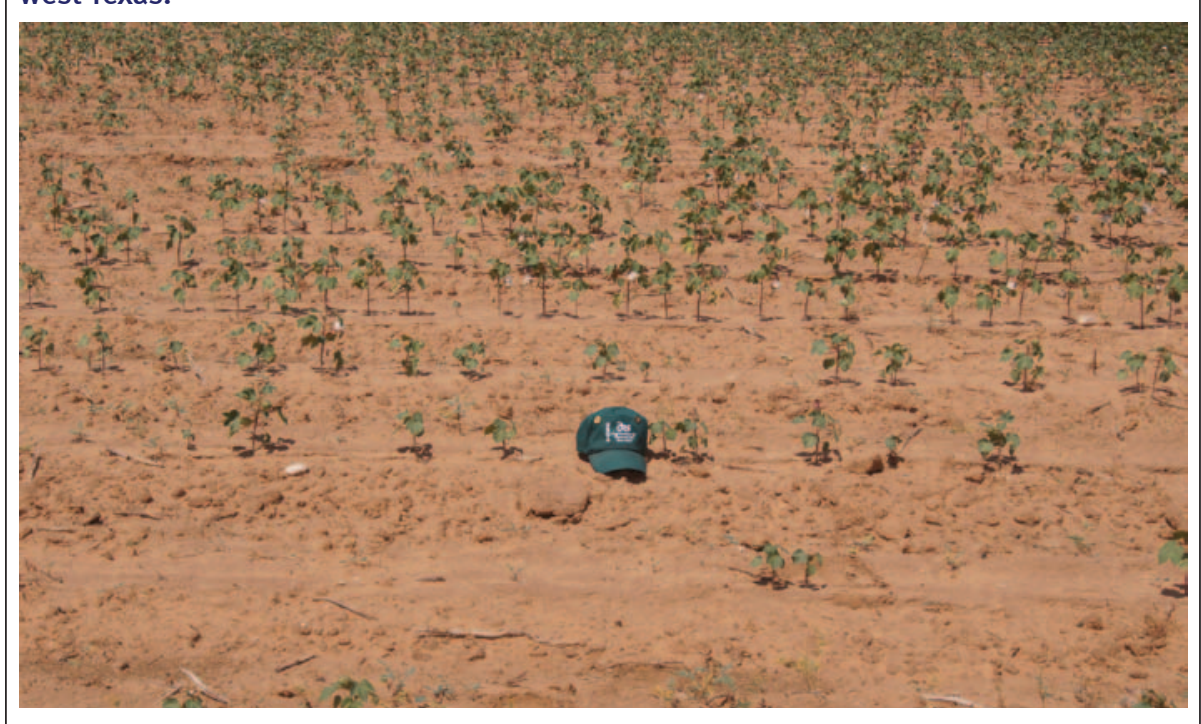

\section{Figure 8}

Example of a rangeland impacted by the catastrophic 2012 drought in the Great Plains (Texas).

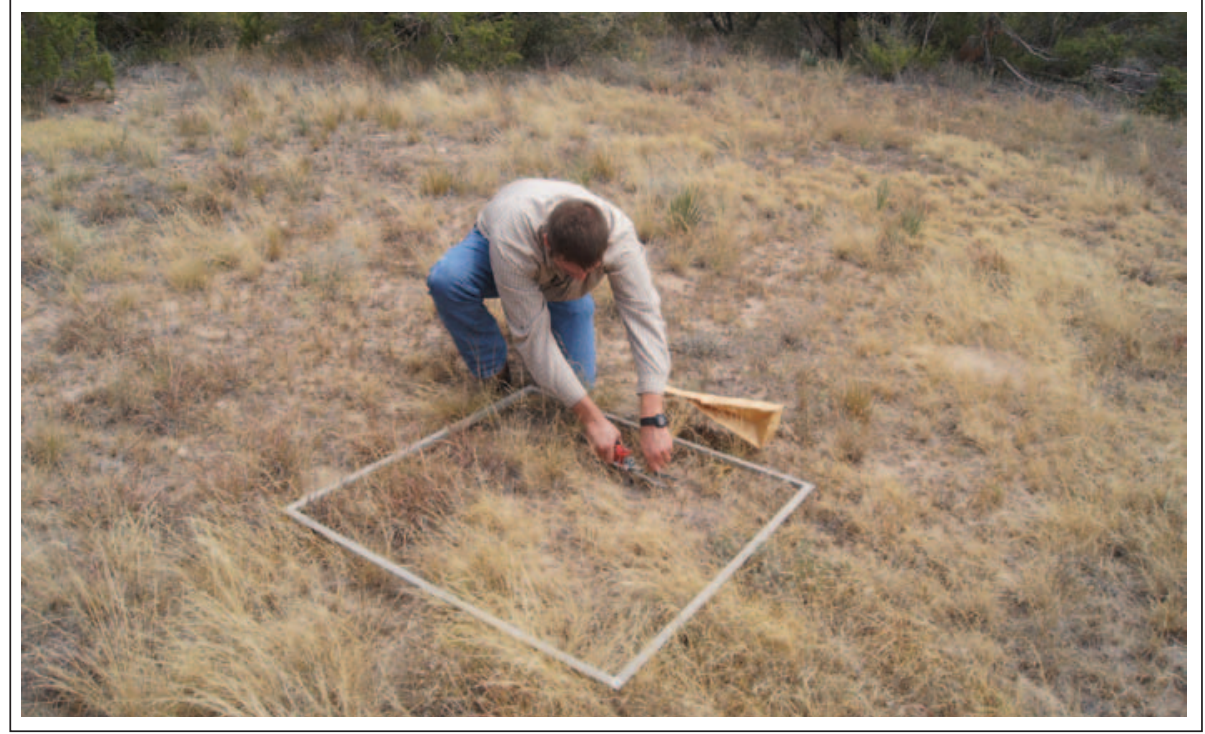

culture be adapted to severe drought and other extreme events?

\section{ADAPTATION TO DROUGHT AND EXTREME EVENTS}

There are numerous options to manage soils, crops, animals, and water resources (Delgado et al. 2011; Lal et al. 2011). Conversion to no-till (NT) farming, in conjunction with crop residue mulch and cover crops, is an important option. The precipitation during the 2011 to 2012 wheat year was only $153 \mathrm{~mm}$ (6 in) $(58 \%$ of normal) at Akron, Colorado.
Conservation practices such as using a NT system produced a significant advantage for the wheat crop when compared to conventionally tilled wheat. Plot studies show that the conventional tillage production system employed prior to wheat planting resulted in $86 \mathrm{~mm}$ (3.4 in) less available soil water at planting compared with the NT system, so the NT system contributed to the conservation of water, which could potentially offer an advantage over the conventional tillage system during drought years. The result of that starting water difference was that the NT system produced $64 \%$ higher biomass than the conventional wheat production system $\left(10,288\right.$ versus $6,589 \mathrm{~kg} \mathrm{ha}^{-1}[9,185$ versus $\left.5,883 \mathrm{lb} \mathrm{ac}^{-1}\right]$ ), which translated into $30 \%$ higher seed yield production with the NT wheat $\left(2,425\right.$ versus $1,860 \mathrm{~kg} \mathrm{ha}^{-1}[36.1$ versus $\left.\left.27.7 \mathrm{bu} \mathrm{ac}^{-1}\right]\right)$.

However, even the NT farming is breaking down under extreme conditions. The 2012 drought has been devastatingly dry for dryland corn production at Akron, Colorado, with only $23 \mathrm{~mm}(0.9$ in) of precipitation falling in the critical six-week period just prior to tasseling and through midgrain fill. This has resulted in total crop failure and no seed production at this location where the research was conducted, even with NT conservation practice implemented (figure 9). The very dry conditions early in the growing season also limited corn biomass production to $1,511 \mathrm{~kg} \mathrm{ha}^{-1}\left(1,349 \mathrm{lb} \mathrm{ac}^{-1}\right)$. However, a positive environmental aspect is that even this small amount of standing biomass produced with NT corn will be an effective conservation practice in reducing wind erosion potential and preventing conditions that were seen in the 1930s Dust Bowl era (figure 1). It is important that we prevent the negative effects of wind erosion with conservation practices since a few large-scale wind erosion events have impacted urban areas in 2011 and 2012. One example is the wind erosion event

\section{Figure 9 \\ Example of catastrophic impact on corn crop caused by the 2012 drought (Colorado).}

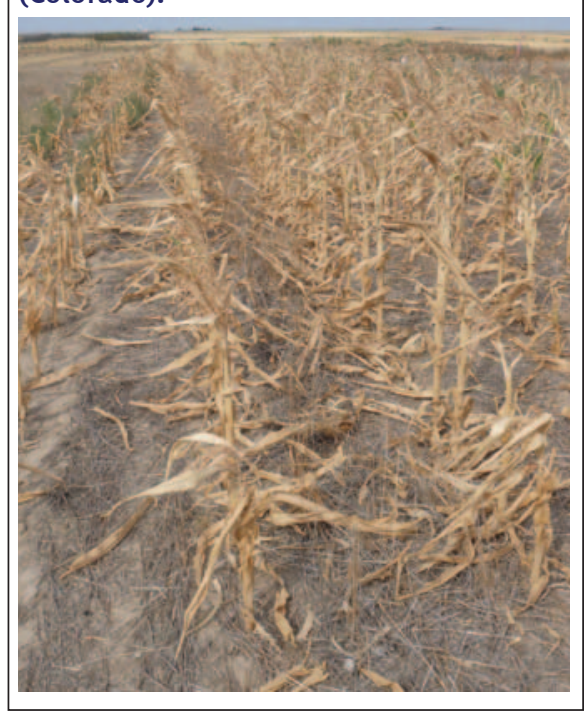


that impacted Lubbock Texas in fall 2011. Additionally, this practice with NT corn will reduce the evaporation rate, capture snow, and store precipitation in the coming months.

Another strategy is to conserve water in the root zone, minimize losses by runoff and evaporation, and transform blue (fresh surface and groundwater) and grey (urban wastewater) waters into green water (fraction of rainfall that is stored in the soil). It is estimated that with proper management, as much as $85 \%$ of incident precipitation may be green water available for crop growth rather than the $50 \%$ or less commonly observed due to excessive runoff and evaporation common with conventional farming practices. Thus, water conservation, harvesting, and recycling are all important.

Integrated nutrient management, a judicious combination of chemical fertilizers with organic amendments (compost, biosolids), is needed to enhance soil organic matter content and maximize crop water use efficiency. Ability of mineral soils to hold water increases with the increase in soil organic matter content. Thus, best management practices of land use and management should enhance soil and ecosystem resilience to drought and other abiotic and biotic stresses.

In addition to time of planting, seeding configuration (bunch planting) and plant populations are appropriate agronomic considerations. Choice of crop species, depending on site-specific considerations, is appropriate to enhance crop diversity, including complex crop rotations, agroforestry, and integration of crops with livestock and trees. Vegetative barriers and terraces may enhance water storage, reduce the evapotranspirative stressor of wind, and minimize risks of wind erosion.

\section{LINKING FARM TO CAPITOL HILL}

While devastating crops, disrupting navigation in the Mississippi River, and jeopardizing global food security, the drought has also provided an opportunity to revisit agricultural systems of managing soils, crops, water, and animals. Are current practices sustainable, especially under conditions of harsh, uncertain, and abruptly changing climate? Are our agricultural policies compatible with reality?
The drought of 2012 should inspire the researchers, extension agents, land managers, and policy makers to revisit these questions. To avoid another "dust bowl" of the 1930s, it is the time to assess the nation's soil and water resources and rethink how we use the natural resources. The drought of 2012 reminds us that soil and water resources must never be taken for granted.

There must be a continuous and open dialogue between researchers on the one hand and land managers and policy makers on the other. Together, we must move away from a piecemeal and crisisdriven approach, and adopt holistic and integrated national policies aimed at sustainable management of limited and fragile natural resources. Farmers may be appropriately incentivized through payments for generating ecosystem services (e.g., soil carbon sequestration, improving quantity and quality of renewable fresh water resources, enhancing biodiversity, increasing use-efficiency of inputs). The myopic strategies of short-term economic gains must be replaced by those of longterm sustainable use of the finite natural resources of soil and water.

\section{REFERENCES}

Delgado, J.A., P.M. Groffman, M.A. Nearing, T. Goddard, D. Reicosky, R. Lal, N.R. Kitchen, C.W.
Rice, D. Towery, and P. Salon. 2011. Conservation practices to mitigate and adapt to climate change. Journal of Soil and Water Conservation 66(4):118A-129A.

Lal, R., Delgado, J. A., Groffman, P. M., Millar, N., Dell, C., and Rotz,A. 2011. Management to mitigate and adapt to climate change. Journal of Soil and Water Conservation 66(4):276-285.

Schwalm, C.R., C.A. Williams, K. Schaefer, D. Baldocchi, T.A. Black, A.H. Goldstein, B.E. Law, W.C. Oechel, K.T. Paw U, and R.L. Scott. 2012. Reduction in carbon uptake during turn of the century drought in western North America. Nature Geoscience 5:551-556.

Simeral, D. 2012. Current U.S. Drought Monitor. http://droughtmonitor.unl.edu/.

USDA. 2012a. 2012 Secretarial Drought Designations - All Drought. http://www.usda. gov/documents/usda-drought-fast-track-designations-090512.pdf.

USDA. 2012b Crop Progress. USDA National Agricultural Statistics Service, Agricultural Statistics Board. Released September 12, 2012. ISSN: 1948-3007. http://usda01.library.cornell.edu/usda/nass/CropProg//2010s/2012/ CropProg-09-10-2012.pdf.

USDA. 2012c. Crop Production. USDA National Agricultural Statistics Service, Agricultural Statistics Board. Released September 12, 2012. ISSN: 1936-3737. http://usda01.library.cornell.edu/usda/nass/CropProd//2010s/2012/ CropProd-09-12-2012.pdf. 